\title{
Study on the Construction Path of China's Smart Community
}

\author{
Jieni Zhu \\ University of Electronic Science and Technology of China \\ Chengdu, P.R. China 611731
}

\begin{abstract}
In recent years, as the concept of smart city widely spreads, smart city as a new means of urban governance, not only changes people's life, but promotes China's modernization in a quick speed. Thus, as the basic modules of smart city, smart community plays an indispensable role. At present, China lacks experience in the construction of smart community. Studies on construction methods and concrete measures are not sufficient. In view of this, this article, under the background of the development of smart City, analyzes the status quo and problems of smart community construction, and puts forward some suggestions on the construction of smart community on the basis of theory.
\end{abstract}

Keywords-smart community; modernization; urban governance; construction

\section{INTRODUCTION}

With the social development of Chinese economy, grassroots governance should constantly realize innovation, advance with the times, positively explore the social governance method and mode, and constantly develop modernization of social governance level and capacity. In recent years, Chinese government has proposed to regard social management innovation, contradictory resolution and fair and honest law enforcement as three key contents. In the process of promoting the grassroots governance in China, it is necessary to positively carry out social management innovation theory and practice study and finally ensure Chinese prosperity and social harmony and stability. Under the overall environment of innovative social management mode, many cities carry out the construction of the smart cities. As the basic constituent module of smart cities, governments, relevant enterprises and academic circles at all levels positively carry out the construction of "smart communities", speed up the construction of smart community, and better serve for the masses. Therefore, community's action of serving for people and basic management can be greatly developed. Communities are short of the conventional service modes, lack of modern science supporting strength and lagging information collection channels. It is necessary to carry out relevant theoretical studies on the smart communities and depend on the effective exploration of digitalization and intelligence pattern, so as to establish the public autonomy management, harmonious interaction of government management, and sharing construction. The close combination of communities and urban management finally realize the grass-roots management service system with vitality and diversified governance [1]. The author gave some measurements and suggestion on some problems in such community construction.

\section{THE CONNOTATION ANALYSIS OF THE SMART COMMUNITY}

With the constant development of informatization, the network role in social management is increasingly important. The so-called "smart communities" depends on the highefficient utilization of big data and integrates with all community information resources to finally construct the grass-roots community service digital platform with "interconnection, information sharing, one-stop acceptance, bar-block combination, collaborative transaction and highefficient standardization". In daily life of the masses, the intelligent application is embedded in it to firmly control advantages and convenience brought by scientific innovation. Meanwhile, these advantages are maximized. By constructing a series of platform and demonstration work, it is necessary to positively promote technical $R \& D$ and build smart environment. Finally, by forming the scientific management and life mode, it is necessary to construct the new community form facing to the future. In the end, the comfortable, modernized and smart life environment is provided for the masses [2-3]. The author thought that in the constructive process of the "smart cities", "smart communities" are considered as the basic constitutions. During the process, "smart communities" belong to the micro-level under the macro level of "smart cities". It is the platform to specifically implement and solve livelihood issues and help them to develop.

\section{CONSTRUCTION STATUS AND PROBLEMS OF THE SMART COMMUNITIES}

As early as 1989, smart communities started to be constructed and developed in European and American developed areas. At the beginning, it was developed towards networking and intelligence, and then visualization, informatization and servitization. The service range has been constantly developing from the resident communities to surrounding business districts. With the arrival of the information era, the public life has the overwhelming changes for networking convenience. People's daily life is not limited to concern resident environment, transportation, 
housing, medical treatment and social insurance, but concern the communication services, their external exchange communication, community property management, and public life security prevention. It is urgent to improve the management level of smart communities. With the proposal of "internet + " by Chinese government, the construction of smart communities is able to be developed rapidly.

However, recently, based on the systematic studies on smart communities and influences of costs and consumption level, the smart community development is extremely unbalanced. Moreover, most of them focus on the metropolis with developed economy. Generally speaking, it refers to construct the smart service function system and record community data. It is based on handy service for the public, community support for the elderly and community health. The products and technologies of smart communities are kept in the initial stage. The community construction standards and specifications are relatively insufficient. The "intelligent" degree is lower. By taking the current domestic security system as an example, the alarm system generally applies the combination of telephone wire and wireless frontend services. Such a method will relatively rely on telephone communication and generate more other expenses. The indoor alarm system needs owners to switch manually. Moreover, different security devices also have the corresponding problems. Meanwhile, there are no domestic systematic standards on smart communities, but it still belongs to the construction stage by feeling, resulting in certain problems in relevant product quality and service functions. In this way, it becomes very difficult to do management maintenance and this will result in influences on the future data acquisition and analysis disposal.

\section{The COnStruction Path of the SMARt Cities}

We must have the profound cognition on the development status and difficulties on the current Chinese smart communities, figure out ideas, take feasibly effective measures and construct the smart communities with Chinese characteristics step by step as in "Fig. 1".

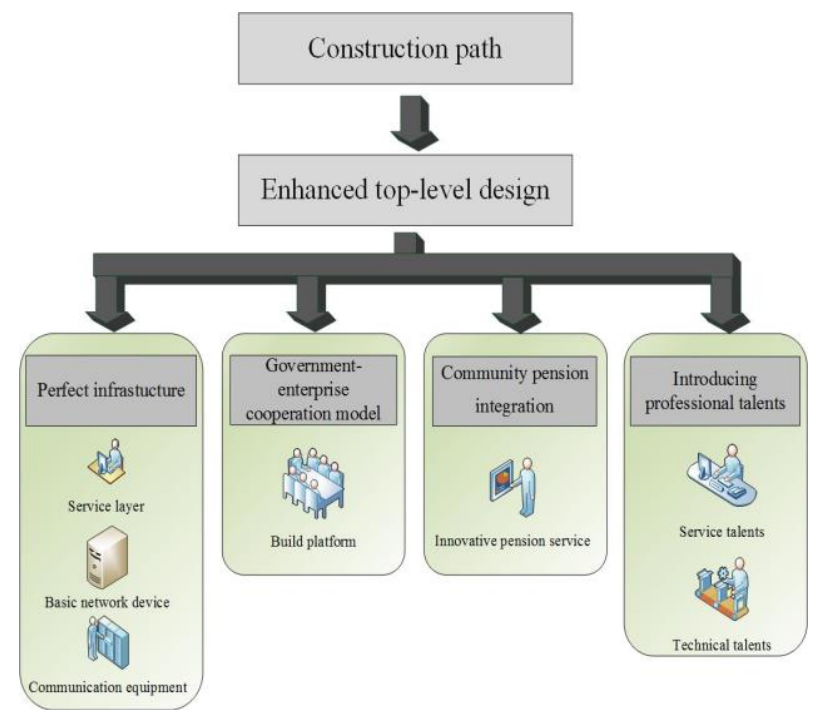

Fig. 1. The graph of the construction path.

\section{A. Reinforce the Top Design and Promote Community Management Planning and Standard Construction}

The top design of smart communities is to define the constructive objectives on the central or the provincial levels, formulate the uniform planning of "smart cities", unify the technical standards and specifications, take measures for smart communities step by step, and realize collaborative and staging responsibilities.

First of all, in the process of constructing the smart communities, the primary task of governments at all levels is to have the profound understanding on the basic livelihood demands in the area, combine constructive planning with the actual status, formulate and scheme with clear rights and liabilities and uniform deployment, and construct smart communities that conform to demands in the city and area. Secondly, the community standardization construction is the important foundation to ensure the construction of smart communities. It is necessary to analyze the smart degree and constructive status of different cities, and conduct the systematic analysis for resource sharing and information exchange in the constructive process. The government should enlarge the investment strength on communities, social organizations and social workers, reinforce the standardization construction for smart communities, positively cultivate social organizations through the governmental purchasing services, and guide social workers to actively participate in social management and social services. The government should positively reinforce the platform construction of smart communities and live up to handle affairs with places, devices and capital. The government provides social service items, greatly guides and cultivates social organizations and social workers to participate positively, and fully develops the platform management role of "smart communities". With the pivotal role of "social organizations" and the core role of "social workers", it is necessary to constantly promote the social governance ability and modernization level [6].

\section{B. Perfect Service Foundation Facilities and Service Facility Network in "Smart Communities"}

Scientific layout should be arranged for relevant service supporting facilities of "smart communities". Because of many requirements for community life process, based on the urban-rural planning and overall planning of land utilization, it is necessary to confirm the overall construction scale in communities. Based on the community population, public demands and regional situations, after confirming the overall facility quantity, layout and constructive mode, it is necessary to do planning design and match with corresponding entertainment and management control facilities. Meanwhile, by integrating and utilization existing facilities in communities, the sharing degree between service facilities in adjacent communities can be finally improved.

As speeding up the construction of communication network facilities in smart communities, effectively developing grass-roots coordinative advantages in communities, and conducting the constructing the "smart communities", it is necessary to do the effective connection with the urban smart construction projects and reinforce the 
cooperation with telecommunication and broadcasting. For wired and wireless communication facilities in the communities, it must speed up construction and perfection, provide the excellent network space for the public life, and speed up the optical fiber engineering, so as to ensure that the entire community service facility space can be fully covered. It is necessary to follow up with the era development and positively promote the wireless community network construction, especially for WIFI and 4G. In addition, it must integrate, transform and construct the digital community television network and ensure that the community communication network can adapt to the new generation of digital television transmission demands [7]. Then, it is necessary to speed up constructing the relevant network facilities, so that wired and wireless networks can realize advantageous complementation and positively establish the all-round coverage of information network.

\section{Reinforce the Government-enterprise Cooperation to Construct the Smart Community Service Platform}

For different areas, it is necessary to effectively utilize technologies, capital and policies, establish the diversified smart community mode, and change the smart community construction of governmental dominance into other modes, such as enterprise dominance or government-enterprise cooperation mode. In the constructive process, it must develop the benign competitive role on service level improvement, but also should give effective consideration to the governmental planning, and speed up promoting the smart community development. In the smart communities, it is necessary to speed up information technology construction, so as to provide the high-quality services for the social people. By virtue of effective application of cloud calculation, big data and internet of things and cooperation with property enterprises, it is necessary to construct the smart, integrated and government-enterprise service platform, hoping that the masses can enjoy high-quality community services.

\section{Create the Pension Service Mode and Establish the Aging Integration of Smart Communities}

By combining with the special national situations, according to the statistics of national statistics, until 2016, the proportion of aged population has been up to $16.7 \%$. China has already stepped into the aging society, showing the social pattern of "aging before getting rich". Facing to the traditional aging mode with the primary family aging, the construction of the smart community is extremely crucial. As conducting the smart communities, it is necessary to construct the aging nursing management system, collect and analyze information data of the aged, so as to provide timely and necessary services for them, and ensure the aged, community aging institutions and children can realize timely interconnection, and construct the database subsystem, emergency subsystem, and life service subsystem. According to the fundamental information of the aged, it is necessary to analyze their life status and nursing situation and fully combine with community aging services to carry out study. By constructing the smart aging call-out information platform, construct the aging service information management system and construct the cloud service website to build the smart aging communities. The "internet_home aging" mode constructed on the community service center project platform can be used to construct the social work service station, steward reception service station. The former is based on the public social work and helps the aged and groups, while latter uses the "internet + " philosophy to construct the one-stop network service platform integrating with family education and life and depends on the online payment and offline experience to provide the apartment steward services for communities. Depending on the effective utilization of big data advantages, it is necessary to establish the different information service platforms of the cloud community service center, establish the mediation rooms, literary form centers and service halls. In the smart communities of Nanjing Qinhuai district, the pension pattern means that the pickers answering the phone. The aged can connect the aging center by one key, while workers in the aging center depend on the computers to look up aging information, so that information can be transferred to units with demands.

It is necessary to promote and apply the smart aging products and APP. At present, in the current market, there are multiple types of the smart aging products, such as wearable, unconscious contact and mobile types. There are numerous types, but the market effects are not prominent, because there products not only have difficult operation, but also have weak practicability. For young people, some operation is convenient, but it is hard for the aged to operate or accept it. As a result, they won't use these products. In addition, some products may be convenient for the aged, but they are expensive. Hence, these products are also abandoned [8].

\section{E. Introduce the Professionals of Smart Communities and Improve Service Efficiency}

The introduction of professional talent is the key factor of the innovation and development of the wisdom of the community, the community needs to create a good physical environment and humanistic environment of "wisdom" agglomeration and attract talent, on the other hand, governments at all levels should use policy and financial resources, and encourage market players to participate in the intelligence community personnel training to. The introduction not only refers to the introduction of talent from the outside, also include the introduction of management ideas and expertise from outside, but also to strengthen the internal training of social workers to carry out related business and skills training, training of basic service personnel do a good job in practice, improve the overall quality of talent and external grassroots service personnel the introduction of high-tech talents ideological quality, implementation for the rest of the organization, to create good conditions of thought.

\section{CONCLUSION}

For smart community system, the construction process is long-term and systematic work. Based on the smart city development and harmonious social construction, as 
constructing the smart communities, it is necessary to complete top design and fully utilize the community management networking technology system, thus it can be connected with the dynamic technical system of the community planning, promote the planning construction of smart communities, combine with different features, and try to properly solve existing contradicts and problems, learn to walk before one can run, and finally establish the perfect smart community service system. In the smart community management and service system, it is necessary to reinforce resident services, provide individualized services, regulate daily activities of community residents, shape smart community lifestyle, improve community life quality, and build more suitable community environment. It is necessary define the future development direction of smart communities, combine with relevant theoretical research contents of relevant theories, continuously perfect foundation facilities, and finally embed smart communities in smart urban system.

\section{REFERENCES}

[1] Yu Hongyi, Smart City: Vision, Planning and Action Strategies[M], Beijing BUPT Press, 2012: 49;

[2] Research Group of China Telecom Smart City, Road of Smart CityScientific Governance and Urban Individuality[M], Beijing: Electronic Industry Press, 2011: 378;

[3] Bloomfield, Green City: Sustainable Community Development Guide[M], translated by Zhang Mingshun, Dan Yingjie and Zhang Xuehua, Beijing Business Administration Press, 2007: 41;

[4] Zhang Peng, Wang Yibin and Shen Yumei, et al, the Study of the Smart Communities based on the Urban-rural Integrated Information Service Platform[J], Chinese Management Informationization, 2012, 15(6): 83-84;

[5] Zheng Conzhuo, GuDedao and Gao Guangyao, The Countermeasure Study on the Smart Community Service System Construction[M], Scientific Management Study, 2013, Vol.(9);

[6] Gou Shenyue, Chai Yanwei and Ma Xiujun, the Concept, Mode and Framework of the Human-oriented Smart Communities[J], Modern Urban Study, 2014(10): 13-24;

[7] Li Chunyou and GuJiajun, the Overview of Overseas Smart City Study[J], Software Industry and Engineering, 2014(3): 50-56.

[8] A RODZI,A R SHARIF,N AHMAD. Smart city components architecture[C]. Computational Intelligence, Modelling and Simulation,CSSim09. International Conference on IEEE,2009: 93-97. 